\title{
The World's Tallest Tropical Tree in Three Dimensions
}

\begin{abstract}
Alexander Shenkin ${ }^{1}$, Chris J. Chandler ${ }^{2}$, Doreen S. Boyd ${ }^{2}$, Toby Jackson ${ }^{1,3}$, Mathias Disney ${ }^{4,5}$, Noreen Majalap ${ }^{6}$, Reuben Nilus ${ }^{6}$, Giles Foody ${ }^{2}$, Jamiluddin bin Jami ${ }^{7}$, Glen Reynolds ${ }^{7}$, Phil Wilkes ${ }^{4,5}$, Mark E. J. Cutler ${ }^{8}$, Geertje M. F. van der Heijden ${ }^{2}$, David F. R. P. Burslem ${ }^{9}$, David A. Coomes ${ }^{3}$, Lisa Patrick Bentley ${ }^{10}$ and Yadvinder Malhi ${ }^{1 *}$
\end{abstract}

\begin{abstract}
${ }^{1}$ Environmental Change Institute, University of Oxford, Oxford, United Kingdom, ${ }^{2}$ School of Geography, University of Nottingham, University Park, Nottingham, United Kingdom, ${ }^{3}$ Department of Plant Sciences, Cambridge University, Cambridge, United Kingdom, ${ }^{4}$ Department of Geography, University College London, London, United Kingdom, ${ }^{5}$ NERC National Centre for Earth Observation (NCEO), Leicester, United Kingdom, ${ }^{6}$ Forest Research Center, Forestry Department, Sandakan, Malaysia, ${ }^{7}$ South East Asia Rainforest Research Partnership (SEARRP), Danum Valley Field Centre, Lahad Datu, Malaysia, ${ }^{8}$ School of Social Sciences, University of Dundee, Dundee, United Kingdom, ${ }^{9}$ School of Biological Sciences, University of Aberdeen, Aberdeen, United Kingdom, ${ }^{10}$ Department of Biology, Sonoma State University, Rohnert Park, CA, United States
\end{abstract}

OPEN ACCESS

Edited by:

Daniel Friess,

National University of Singapore, Singapore

Reviewed by: Marion Pfeifer,

Newcastle University, United Kingdom

*Correspondence:

Yadvinder Malhi

yadvinder.malhi@ouce.ox.ac.uk

Specialty section:

This article was submitted to

Tropical Forests,

a section of the journal

Frontiers in Forests and Global

Change

Received: 29 March 2019 Accepted: 30 May 2019

Published: 18 June 2019

Citation:

Shenkin A, Chandler CJ, Boyd DS,

Jackson T, Disney M, Majalap N,

Nilus R, Foody G, bin Jami J,

Reynolds G, Wilkes $P$, Cutler MEJ, van der Heijden GMF, Burslem DFRP, Coomes DA, Bentley LP and Malhi Y

(2019) The World's Tallest Tropical

Tree in Three Dimensions.

Front. For. Glob. Change 2:32.

doi: 10.3389/ffgc.2019.00032
Keywords: Tree height, tropical forests, limits to height, angiosperm, LIDAR-remote sensing, terrestrial laser scanning, UAV (unmanned aerial vehicle)

Here we report the recent discovery of the world's tallest tropical tree (Shorea faguetiana), possibly the world's tallest angiosperm (flowering plant), located in the rainforests of Sabah, Malaysian Borneo. In addition, we provide a novel three-dimensional exploration of the dimensions of this remarkable tree and use these data to speculate on what drives the limits of tree height. Through consideration of both mechanical (risk of wind damage) and ecophysiological constraints we argue that this tree is close to the maximum height possible for angiosperms, around $100 \mathrm{~m}$, and discuss more broadly what the nature and location of this tree imply about the limits to tree height. We propose to name this remarkable tree "Menara," Malay for "tower."

This tall tree ("Menara") was first identified during an airborne Light Detection and Ranging (LiDAR) survey conducted in 2014. The tree is located in the Danum Valley Conservation Area (DVCA) in Sabah, which also holds the previous record holder for tallest tropical tree ${ }^{1}$. This tree is located at an elevation of $436 \mathrm{~m}$ a.s.l on a slope of $33^{\circ}$ and an aspect of $72^{\circ}$. Because airborne LiDAR is prone to significant errors when used to estimate heights of individual trees (Wan Mohd Jaafar et al., 2018), and because hilly topography will likely exacerbate those errors, record claims need to verified by reliable and calibrated instruments (such as Terrestrial Laser Scanning [TLS]) and, ideally, manual tape measurement. Hence, following the airborne identification, researchers returned in August 2018 to manually measure trunk diameter and conduct TLS scans and a drone flight to construct a detailed 3D model (Figure 1) and to calculate tree height and other dimensions ${ }^{2}$. A further visit was conducted in January 2019, during which the tree was climbed to the top of its crown so the height could be directly verified with a measuring tape (Figure 2).

\footnotetext{
${ }^{1}$ The tallest tropical tree that has been locally climbed and measured is a $94.1 \mathrm{~m}$ Shorea faguetiana reported in the Danum Valley Conservation Area in 2017 (https://www.theborneopost.com/2017/03/11/worldstallest-tropical-tree-in-danum-valley/), the tallest of 50 tall trees reported from an airborne lidar survey in 2016 (https://news.mongabay.com/2016/06/tropics-tallest-tree-found-in-malaysia/). In May 2018 a media report suggested a taller tree has been measured in Tawau Hills National Park, in Sabah (http://www.dailyexpress.com.my/news.cfm?NewsID=125818).

${ }^{2} 3 \mathrm{D}$ data are available for download at https://doi.org/10.5287/bodleian:KzNpxEOg5, 3D data are viewable at https://skfb.ly/ 6KXXH, and UAV footage is viewable at https://www.eci.ox.ac.uk/news/2019/0408.html.
} 


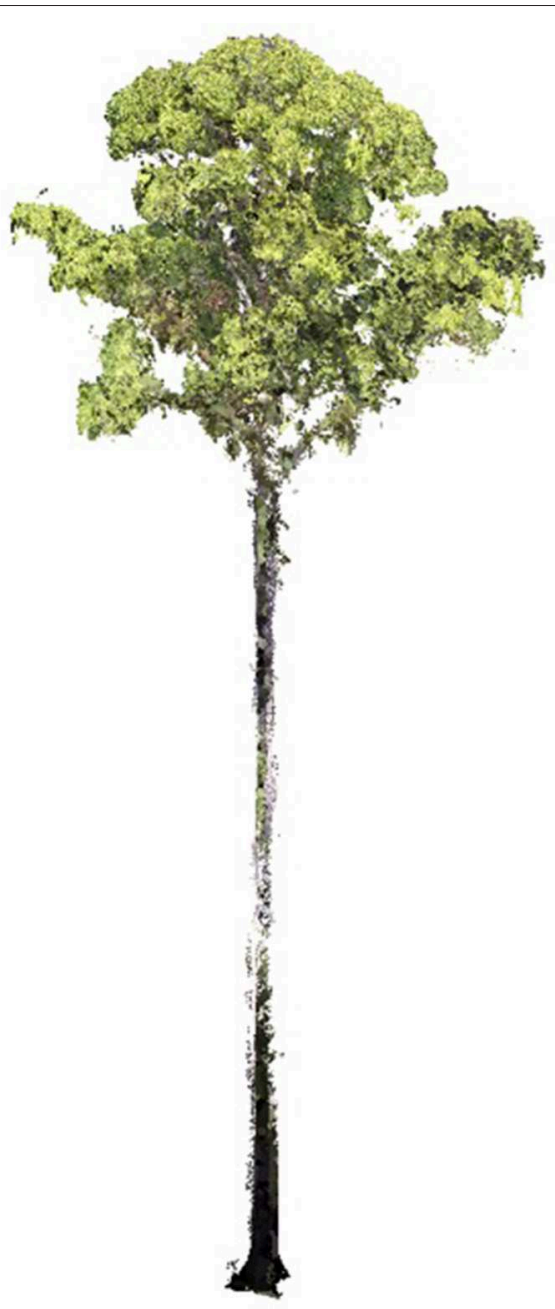

FIGURE 1 | A 3D point cloud of the tallest tropical tree generated from fusing 2 data sources: TLS pointclouds from a RIEGL VZ-400 (RIEGL Laser Measurement Systems $\mathrm{GmbH}$ ); and pointclouds derived from applying structure-from-motion algorithms to video from a UAV flight up and around the tree. Still images were extracted from the UAV-based video footage using ffmpeg, and these were then used to create pointclouds using Pix4Dmapper software package (Pix4D SA,. Switzerland). The TLS and UAV-dervied pointclouds were fused together using CloudCompare software (version 2.10.1, retrieved from http://www.cloudcompare.org/), and the TLS points were colored based on the color of the nearest neighboring UAV point. Interactive data and downloads can be found at https://skfb.ly/6KXXH and Shenkin et al. (2019).

"Menara" is a Shorea faguetiana tree (common name Yellow Meranti), of the Dipterocarpaceae family, a taxon that dominates the humid lowland rainforests of SE Asia. As verified by measuring tape, it has a height of $100.8 \mathrm{~m}$ (distance to lowest part of the buttress; distance to lowest part of bole is $98.90 \mathrm{~m}$, distance to highest base point of bole $96.26 \mathrm{~m}$ ). This tree exceeds previous record holders including another tree in Danum Valley estimated at $94.1 \mathrm{~m}$ by airborne LiDAR (ALS) in 2016 as well as a media report of a $96.9 \mathrm{~m}$ Shorea faguetiana recorded in Tawau Hills National Park, Sabah, in May 2018 ${ }^{1}$. This makes it

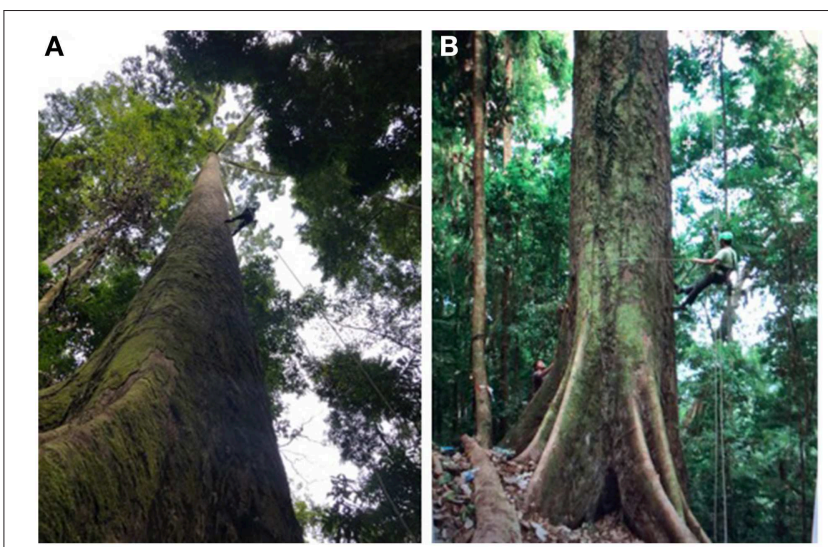

FIGURE 2 | Jamiluddin (Unding) bin Jami climbing the tree in January 2019 to verify its (A) height and (B) diameter above buttress.

unambiguously the tallest tropical tree yet recorded anywhere in the world.

The tree is also potentially the tallest angiosperm (flowering plant). From the lowest point of the buttress, "Menara" exceeds the $99.67 \mathrm{~m}$ record of tape-drop measurements of the "Centurion" tree in 2016, a Eucalyptus regnans in Tasmania, Australia $^{3}$. Debates in protocols in how height-to-base is defined (to the lowest above-ground point, or to the median or mean ground-level point), and uncertainty in more recent rangefinder measurements of "Centurion" (Larjavaara and Muller-Landau, 2013) leave some room for ambiguity between these two giant trees, but "Menara" is now clearly a contender for the world's tallest angiosperm. For comparison, the tallest gymnosperm on record is the "Hyperion", a coastal redwood (Sequoia sempervirens) in California with a height of $115.7 \mathrm{~m}$ (Sillett et al., 2010) ${ }^{4}$.

The TLS scan and drone flight enable us to establish additional dimensional information about this tree, and thus examine the mechanics of such giant trees. Using literature values of wood density for this species, we estimate that the tree has an aboveground fresh biomass of $81,500 \mathrm{~kg}$ (dry biomass $77,400 \mathrm{~kg}$ ), of which only $5 \%$ is in the crown (which has diameter $40 \mathrm{~m}$ ) and $95 \%$ is in the trunk. The stem is very straight, with the center of mass at $28 \mathrm{~m}$ above the ground and only displaced by $0.6 \mathrm{~m}$ from the central vertical axis, suggesting this tree is highly symmetrical and well-balanced despite being situated on strongly sloping ground. Menara's diameter above the buttress is $212 \mathrm{~cm}$ (Figure 2B). This conforms with the general and remarkably slender architecture of dipterocarp trees; in stark contrast, the Centurion eucalyptus has a diameter of $405 \mathrm{~cm}$.

Tree height may be limited by mechanical, ecophysiological, and hydraulic constraints (Niklas, 2007), and perhaps also by

\footnotetext{
${ }^{3}$ Recent (2018) measurements by rangefinder suggest that the Centurion tree may have attained $100.5 \mathrm{~m}$, but laser rangefinder measurements carry greater uncertainty and this value has not yet been verified by tape-drop. https://www. thetreeprojects.com/news/australias-tallest-tree-surpasses-metres.

${ }^{4}$ https://www.sfgate.com/bayarea/article/HUMBOLDT-COUNTY-World-stallest-tree-a-2550557.php.
} 
genetic programming (Becker et al., 2000). Is this tree near the likely mechanical limits for angiosperm tree height? By having a spreading crown and therefore a high center of mass, most simple-crowned angiosperms are likely to have stronger mechanical constraints on their height than gymnosperms with a more tapering architecture (Jaouen et al., 2007). Interestingly, the tall Eucalyptus regnans appears to have a very different, superficially somewhat gymnosperm-like architecture, with a wide trunk diameter and short branches extending throughout much of its length. An analysis based on the three dimensional model of Menara (Jackson et al., 2019b) suggests that this tree is a long way from buckling under its own weight (it would need to attain approximately $255 \mathrm{~m}$ in height to hit that threshold), but is vulnerable to breakage under moderate wind speeds, and therefore may be close to a wind-related maximum height constraint. The methods employed in this mechanical analysis are excluded here for readability, but are explained in detail in (Jackson et al., 2019a).

The tree is partially sheltered by a ridge and is in a local topographic low-point, which is likely to have facilitated its growth to record heights. The effect of this ridge as a form of shelter from wind is clear from the differences in average tree heights on either side of the ridge (Figure 3A). Spatial patterns of tree heights across the DVCA in relation to aspect (Figure 3C) and slope (Figure $3 \mathrm{D}$ ) suggest that the tallest trees $(>70 \mathrm{~m})$ may only reach such heights on aspects sheltered from the prevailing wind and with a slope steep enough to act as a wind barrier. This distinct spatial patterning of the largest trees in relation to topography suggests that wind stress may be the prevailing constraint on maximum tree height.

Ecophysiological constraints may also play a role. Jensen and Zwieniecki (2013) examined the basic physiological and geometrical constraints of the carbohydrate distribution network (pumping sugars from the leaves to the rest of the tree) and argued that, under ideal conditions (good moisture supply and low wind speed, as found in Sabah), the maximum possible height of angiosperm trees should be $104 \pm 6 \mathrm{~m}$. They show from an examination of leaf size data (predominantly from tropical SE Asia) that leaf size becomes increasingly constrained with increasing height, and that above $\sim 100 \mathrm{~m}$ height angiosperm leaves cannot maintain sufficient carbohydrate transport speeds in the phloem to maintain tree metabolism. Hydraulic constraints may also play a role: as trees grow taller, large negative pressures due to the weight of the long water columns suspended from crown to soil may ultimately limit leaf expansion and photosynthesis, even with ample soil moisture. From ecophysiological studies of California redwoods, Koch et al. (2004) predicted a maximum gymnosperm tree height of $122-130 \mathrm{~m}$. Angiosperms, with their generally more efficient but less conservative hydraulic networks, are likely to be more constrained than gymnosperms by hydraulic constraints. These hydraulic constraints may drive limits to
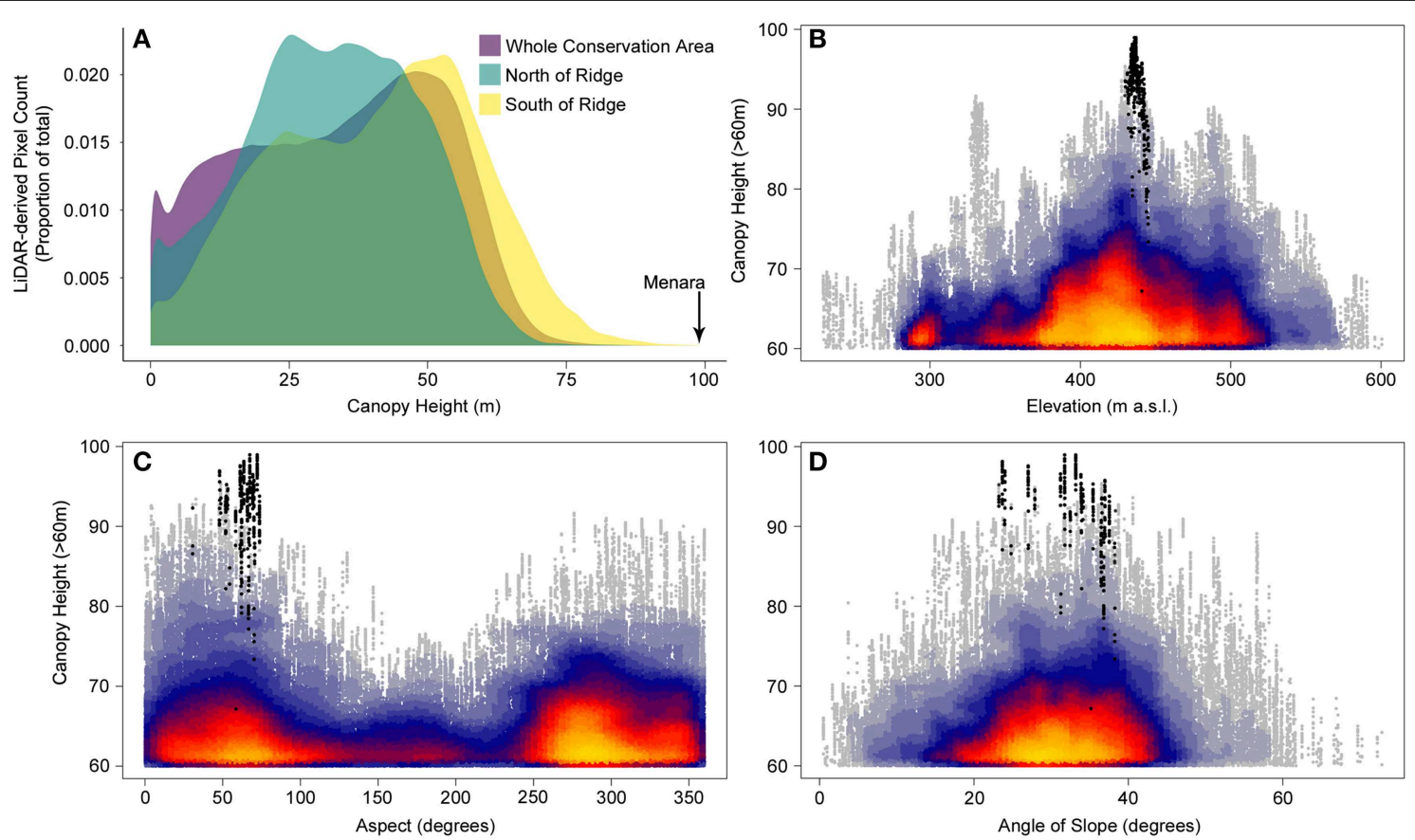

FIGURE 3 | (A) The count of LiDAR derived canopy heights for the local area surrounding the tree showing the difference in average tree heights on either side of the ridge in comparison to the DVCA as a whole. Relationship between canopy height for the tallest trees (>60 m) and (B) elevation, (C) aspect and (D) angle of slope. Black points represent pixels within the crown boundary of Menara. The airborne LiDAR data were collected by the UK Natural Environment Research Council (NERC) Airborne Research Facility (ARF) in 2014 using a Leica ALS50-II LiDAR system at an average point density of 2.9m-2. Data were first preprocessed on NERC's Data Analysis Node, with further processing carried out in LAStools. Topographic data for the DVCA polygon was extracted and analyzed with the R programming language (R Core Team, 2019), and topographic variables were calculated using the raster R package (Hijmans, 2019). 
tree height (Liu et al., 2019), and the valley where this tree is located may ameliorate these hydraulic limits by maintaining humid soils.

Recent studies have shown that tall trees may be especially vulnerable to droughts (Bennett et al., 2015; Shenkin et al., 2018), likely because they are already close to hydraulic limits. Droughts in Borneo are associated with elevated tree mortality rates (Leighton and Wirawan, 1986; Woods, 1989; Nakagawa et al., 2000; Van Nieuwstadt and Sheil, 2005), and droughts across the tropics are expected to increase in depth and frequency as climate change proceeds (Malhi et al., 2008). In Borneo, annual precipitation has dropped by over $700 \mathrm{~mm}$ annually since the 1950s, likely due to land use change (McAlpine et al., 2018). Tall trees such as this Shorea faguetiana, which tend to have more cavitation-prone xylem (Liu et al., 2019), may therefore be vulnerable to these changing drought regimes. Perhaps due to its position near a valley bottom, "Menara" may be somewhat insured against droughts; indeed, its crown and foliage appear full and healthy. Thus, valleys may create multiple abiotic conditions that allow trees to grow taller than they would be able to otherwise.

Are there likely to be taller trees out there? The recent spate of records derived from airborne LiDAR surveys ${ }^{1}$ suggests that taller tropical trees may yet be found: we predict that they are almost certainly in northern Borneo, will be of the genus Shorea and probably the species Shorea faguetiana, and they will be found in similarly sheltered locations in the local topography. Given the evidence of mechanical (wind) and ecophysiological constraints as outlined above, it is unlikely that any new tree would be much taller, but probably tall enough to unambiguously break the record for tallest angiosperm. Hence it is likely that the world's tallest extant flowering plant still sits undiscovered somewhere in the forests of Borneo.

This work highlights that in the world's tropical rainforests some of the largest organisms on Earth still await discovery and description. Over the past decade the Sabah Forestry Department has progressively extended the protection of several hundred thousand hectares of forest in the vicinity of the Danum Valley Conservation Area-which is now buffered on all sides by totally protected areas (Reynolds et al., 2011). Further, the Sabah Government has committed, by 2025, to increase the extent of protected forests to $30 \%$ of the State's land area (Sabah Forestry Department, 2018). The discovery of this remarkable tree provides additional recognition to, and impetus for, efforts to conserve these magnificent, biodiverse and record-breaking tall rainforests.

\section{AUTHOR CONTRIBUTIONS}

YM, AS, CC, and DSB wrote the manuscript with input from co-authors. The airborne lidar work and analysis was conducted by CC and DSB, and supported by GF, GR, MC, GvdH, DB, and DC. The terrestrial laser scanning was conducted by AS and supported by YM, MD, LB, and PW. The drone flights and point cloud analysis were conducted by AS. The tree was climbed and its tape height measured by JbJ. The tree mechanics analysis was conducted by TJ. The work in Malaysia was supported and facilitated by NM, RN, and GR.

\section{FUNDING}

We would like to thank the Natural Environment Research Council for funding the airborne remote sensing campaign [HMTF grant NE/K016377/1 to the BALI consortium, YM, $\mathrm{DC}$, and $\mathrm{DB}$ ] + direct access [grant to $\mathrm{MC}, \mathrm{DSB}, \mathrm{GF}$, and $\mathrm{DB}$ ], analyses [grants NE/P004806/1 to MC, DSB, GF, DB, $\mathrm{GvdH}$, and NE/I528477/1 to GvdH, DSB, GF], and groundbased work [grant NE/P012337/1 to YM, MD, and LP]; a European Research Council Advanced Investigator Award [grant number 321131] to YM for funding the UAV work; capital funding from the National Centre for Earth Observation to MD for TLS equipment; LAStools' LASmoons program for a free academic license; an Anne McLaren Research fellowship by the University of Nottingham to $\mathrm{GvdH}$ for funding the tree climbing and the University of Oxford's RCUK OA Grant for funding the publishing of this article. YM is supported by the Jackson Foundation.

\section{ACKNOWLEDGMENTS}

We are hugely grateful to the expedition teams: D. bin Mustapa, M. Asri, M. Channing, A. bin Sailim, A. bin Tamring, F. John, A. bin Jelling and S. Rizan; to the team at Danum Valley: J. Larenus, M. F. nin Abd Karim, R. Elizabath, and F. L. Thomas; to A. Burt for help with TLS data; and to participating agencies: Sabah Biodiversity Center, Chief Minister's Department Office of Internal Affairs \& Research, Land \& Survey Department, Sabah Forestry Department, and Danum Valley Management Committee.

\section{REFERENCES}

Becker, P., Meinzer, F., and Wullschleger, S. (2000). Hydraulic limitation of tree height: a critique. Funct. Ecol. 14, 4-11. doi: 10.1046/j.1365-2435.2000. 00397.x

Bennett, A. C., Mcdowell, N. G., Allen, C. D., and Anderson-Teixeira, K. J. (2015). Larger trees suffer most during drought in forests worldwide. Nat. Plants 1:15139. doi: $10.1038 /$ nplants.2015.139

Hijmans, R. J. (2019). Raster: Geographic Data Analysis and Modeling. R package version 2.8-19. Available online at: https://CRAN.R-project.org/package=raster (accessed May 25, 2019).

Jackson, T., Shenkin, A., Wellpott, A., Calders, K., Origo, N., Disney, M., et al. (2019a). Finite element analysis of trees in the wind based on terrestrial laser scanning data. Agri. Forest Meteorol. 265, 137-144. doi: 10.1016/j.agrformet.2018.11.014

Jackson, T. D., Shenkin, A. F., Majalap, N., Bin Jami, J., Bin Sailim, A., Reynolds, G., et al. (2019b). The mechanical stability of the world's tallest broadleaf trees. BioRxiv [Preprint]. doi: 10.1101/ 664292

Jaouen, G., Alméras, T., Coutand, C., and Fournier, M. (2007). How to determine sapling buckling risk with only a few measurements. Am. J. Bot. 94, 1583-1593. doi: 10.3732 /ajb.94.10.1583 
Jensen, K. H., and Zwieniecki, M. A. (2013). Physical limits to leaf size in tall trees. Phys. Rev. Lett. 110:018104. doi: 10.1103/PhysRevLett.110.018104

Koch, G. W., Sillett, S. C., Jennings, G. M., and Davis, S. D. (2004). The limits to tree height. Nature 428, 851-854. doi: 10.1038/nature02417

Larjavaara, M., and Muller-Landau, H. C. (2013). Measuring tree height: a quantitative comparison of two common field methods in a moist tropical forest. Methods Ecol. Evol. 4, 793-801. doi: 10.1111/2041-210X.12071

Leighton, M., and Wirawan, N. (1986). "Catastrophic drought and fire in Borneo tropical rain forest associated with the 1982-1983 El Nino Southern Oscillation event," in Tropical Rain Forests and The World Atmosphere, ed G. T. Prance (Boulder, Co: Westview Press), 75-102.

Liu, H., Gleason, S. M., Hao, G., Hua, L., He, P., Goldstein, G., et al. (2019). Hydraulic traits are coordinated with maximum plant height at the global scale. Sci. Adv. 5:eaav1332. doi: 10.1126/sciadv.aav1332

Malhi, Y., Roberts, J. T., Betts, R. A., Killeen, T. J., Li, W., and Nobre, C. A. (2008). Climate change, deforestation, and the fate of the Amazon. Science 319:169. doi: $10.1126 /$ science. 1146961

McAlpine, C. A., Johnson, A., Salazar, A., Syktus, J., Wilson, K., Meijaard, E., et al. (2018). Forest loss and Borneo's climate. Environ. Res. Lett. 13:044009. doi: 10.1088/1748-9326/aaa4ff

Nakagawa, M., Tanaka, K., Nakashizuka, T., Ohkubo, T., Kato, T., Maeda, T., et al. (2000). Impact of severe drought associated with the 19971998 El Niño in a tropical forest in Sarawak. J. Trop. Ecol. 16, 355-367. doi: $10.1017 /$ S0266467400001450

Niklas, K. J. (2007). Maximum plant height and the biophysical factors that limit it. Tree Physiol. 27, 433-440. doi: 10.1093/treephys/27.3.433

R Core Team (2019). R: A Language and Environment for Statistical Computing, Version 3.5.3. R Foundation for Statistical Computing, Vienna. Available online at: https://www.R-project.org/ (accessed May 25, 2019).

Reynolds, G., Payne, J., Sinun, W., Mosigil, G., and Walsh, R. P. D. (2011). Changes in forest land use and management in Sabah, Malaysian Borneo, 1990-2010, with a focus on the Danum Valley region. Philos. Trans. Royal Soc. B. 366, 3168-3176. doi: 10.1098/rstb.2011.0154

Sabah Forestry Department (2018). Sabah Forest Policy 2018. Sandakan: Sabah Forestry Department. Available online at: http://www.forest.sabah.gov.my/ images/pdf/publications/DH-Sabah.2018.pdf
Shenkin, A., Bolker, B., Peña-Claros, M., Licona, J. C., Ascarrunz, N., and Putz, F. E. (2018). Interactive effects of tree size, crown exposure and logging on droughtinduced mortality. Philos. Transact. Royal Soc. B. 373:189. doi: 10.1098/rstb.20 18.0189

Shenkin, A., Wilkes, P., Burt, A., Jami, U., Disney, M., Bentley, L.P., et al. (2019). $3 D$ Pointcloud Data of the World's Tallest Tropical Tree to Date. University of Oxford. doi: 10.5287/bodleian:KzNpxEOg5

Sillett, S. C., Van Pelt, R., Koch, G. W., Ambrose, A. R., Carroll, A. L., Antoine, M. E., et al. (2010). Increasing wood production through old age in tall trees. Forest Ecol. Manag. 259, 976-994. doi: 10.1016/j.foreco.2009. 12.003

Van Nieuwstadt, M. G. L., and Sheil, D. (2005). Drought, fire and tree survival in a Borneo rain forest, East Kalimantan, Indonesia. J. Ecol. 93, 191-201. doi: 10.1111/j.1365-2745.2004. 00954.x

Wan Mohd Jaafar, W. S., Woodhouse, I. H., Silva, C. A., Omar, H., Abdul Maulud, K. N., Hudak, A. T., et al. (2018). Improving individual tree crown delineation and attributes estimation of tropical forests using airborne LiDAR data. Forests 9:759. doi: 10.3390/f9120759

Woods, P. (1989). Effects of logging, drought, and fire on structure and composition of tropical forests in Sabah, Malaysia. Biotropica 21, 290-298. doi: $10.2307 / 2388278$

Conflict of Interest Statement: The authors declare that the research was conducted in the absence of any commercial or financial relationships that could be construed as a potential conflict of interest.

Copyright () 2019 Shenkin, Chandler, Boyd, Jackson, Disney, Majalap, Nilus, Foody, bin Jami, Reynolds, Wilkes, Cutler, van der Heijden, Burslem, Coomes, Bentley and Malhi. This is an open-access article distributed under the terms of the Creative Commons Attribution License (CC BY). The use, distribution or reproduction in other forums is permitted, provided the original author $(s)$ and the copyright owner(s) are credited and that the original publication in this journal is cited, in accordance with accepted academic practice. No use distribution or reproduction is permitted which does not comply with these terms. 